of continuous exposure of endemic workers to these harmful substances, including organochlorines (BHC and DDT), organophosphates (temephos and malationa), carbamates (bendiocarb), pyrethroids (deltamethrin) and benzoylureas (diflubenzuron), which are associated with several deleterious health effects, such as neurotoxicity, carcinogenicity and endocrine disruption.

Objective To evaluate data on morbidity and mortality of endemic workers in the state of Rio de Janeiro, Brazil.

Methods The evaluation is part of a multicenter, observational, descriptive and cross-sectional study. 109 death certificates provided by work unions were analyzed through documentation provided by family members and data on work leave, between 1942 and 2018, by the Rio de Janeiro State Nucleus of the Ministry of Health.

Results $70.64 \%$ of workers died at a productive age (40-59 years), with an average of 54 years (SD: 9.77). The main causes of death were diseases of the circulatory system (38.7\%) and cancer (14.7\%). The number of deaths has progressively increased from around 5 annual deaths in 2010 to 40 from 2015 onwards. In addition, various types of illnesses have caused 5,024 instances of work leave.

Conclusion Considering the preliminary results, the occurrence of deaths in working age demonstrate their precocity, with a reduction of at least 20 years in life expectancy. The results show morbidity and mortality and the increase in the number of cases related to the use of agrotoxic, the precarious working conditions and the absence of work process monitoring by workers.

\section{P-436 'STUDIES OF COMMON MENTAL DISORDERS OF ENDEMIC WORKERS IN THE STATE OF RIO DE JANEIRO, BRASIL}

'Priscila Vidal, Victor Figueiredo, Marcus Santos, Gabriel Silveira, Ana Silva, Luiza Dantas, Marcos-Rogério Silva, Ébio-Willis Moreira, Roberto-Paulo Nunes, Socorro Setubal, AntônioCarlos Cardoso, Monica-Regina Martins, Dominique Marçal, Fátima Moreira, AnaCristina Rosa, Leandro Carvalho, Maria-Blandina Santos, Luiz-Claudio Meirelles, Isabele Costa-Amaral, Eline Gonçalves, Ariane Larentis, Liliane Teixeira, Luciana Gomes. ${ }^{1}$ Fiocruz National School of Public Health Sergio Arouca (Ensp)

\subsection{6/OEM-2021-EPI.327}

Introduction Endemic workers are among the categories most exposed to the effects of pesticides used in vector control. They also face unsafe working conditions with reports of bullying, inadequacy or lack of training, and almost non-existent educational processes. Previous studies have observed damage to the mental health of rural workers caused by exposure to pesticides.

Objective To analyze the relationship between mental health and the activities of workers in the fight against endemic diseases in the state of Rio de Janeiro, Brazil in the current situation.

Methods To this end, an online questionnaire was applied with questions related to work, health, sleep quality, and working and health conditions in the pandemic, including the Self-Reporting Questionnaire for screening common mental disorders (CMD). We obtained 139 valid questionnaires and employed the Chi-square and Fisher's exact test for statistical analysis.

Results The study identified the frequency of $43.2 \%$ of symptoms indicative of CMD in the studied population regarding CMD. When stratified by gender, we observed that the occurrence was almost twice more likely in males than in females $(p \leq 0.04)$. Marital status and education were also associated with $\mathrm{p} \leq 0.01$ and $\mathrm{p} \leq 0.05$, respectively. The work associations were sprinkler pump $(\mathrm{p} \leq 0.02)$, referred intoxication symptoms $(p \leq 0.00)$, and the previous diagnosis of depression $(p \leq 0.00)$. Concerning cases of a previous diagnosis of depression, we identified associations with females $(\mathrm{p} \leq 0.03)$; activity involving contact, handling, or application of agrotoxic in the past $(\mathrm{p} \leq 0.04)$; referred symptoms of intoxication $(\mathrm{p} \leq 0.00)$; reported use of malathion in the last decade $(p \leq 0.02)$; activities related to field agent $(p \leq 0.05)$, and suicidal ideas $(\mathrm{p} \leq 0.00)$.

Conclusion The results reinforce that work conditions and processes have been a triggering factor for illness in the studied population. Changes in the work process are necessary to avoid work that is harmful to the worker's health.

\section{P-438 UNMASKING THE TRUTH: A LONGITUDINAL STUDY EXAMINING WORKPLACE PROTECTIVE STRATEGIES, WORKING ARRANGEMENTS, AND THEIR IMPACT ON WORKERS' HEALTH, SAFETY AND PRODUCTIVITY IN NEWFOUNDLAND AND LABRADOR DUR}

${ }^{1}$ Kim Cullen, Dianne P Ford, Amanda Butt, Sumayyah Musa. ${ }^{1}$ Memorial University of Newfoundland, Canada

\subsection{6/OEM-2021-EPI.328}

Introduction Under federal and provincial legislations, employers across Canada have a responsibility to reasonably protect the health and safety of their workforce. The COVID-19 pandemic has created many challenges for employers to meet these responsibilities. Employers have been particularly hindered in their efforts to protect their workers due to changing understandings of COVID-19 risks over time. Knowledge of effective public health measures is continuously evolving, with new evidence emerging almost daily. Workplace-led strategies have been designed and implemented to specifically protect workers from exposure to the COVID-19 virus. What we don't know is the unintended long-term consequences these workplace protection measures may be having on workers' health and ability to work safely during the pandemic.

Objectives To examine the influences of geographical region, sex and gender, industry, occupation, and perceptions of worker autonomy on the relationship between workplace-led strategies to protect workers from exposure to COVID-19 on measures of worker health safety and productivity.

Methods Using a longitudinal survey with a purposive sampling of Newfoundland and Labrador workers at regular intervals over a 12-month period, data were collected across six domains: participant demographics, pandemic-specific workplace policies and practices, working environment (including remote and on-campus work), psychosocial working conditions, physical health and mental health.

Results Findings from the baseline, 3 month and 6-month follow-up surveys will be presented. Preliminary results from this work highlight the challenges faced by workers under remote and standard work arrangements and the relationship among these working conditions and impacts on worker health, safety and productivity during the changing nature of work throughout the COVID-19 pandemic.

Conclusion The outcomes from our research will provide new knowledge through the collection of stakeholder perspectives 